\title{
Influence of infiltration technique and selected demineralization methods on the roughness of demineralized enamel: An in vitro study
}

\author{
Katarzyna Piątek-Jakubek ${ }^{1, A-F}$, Joanna Nowak², A, B, Elżbieta Bołtacz-Rzepkowska ${ }^{1, A, C, E, F}$ \\ ${ }^{1}$ Department of Conservative Dentistry, Medical University of Lodz, Poland \\ ${ }^{2}$ Laboratory of Material Testing, Medical University of Lodz, Poland \\ A - research concept and design; B - collection and/or assembly of data; C - data analysis and interpretation; \\ $D$ - writing the article; $E$ - critical revision of the article; $F$ - final approval of the article
}

Address for correspondence

Katarzyna Piątek-Jakubek

E-mail:katarzyna.piatek-jakubek@wp.pl

Funding sources

The study was financed by the Medical University of Lodz within the framework of financing provided for studies conducted by young research workers and doctoral students (no. 502-03/2-044-01/502-24-029).

Conflict of interest

None declared

Received on January 27, 2016

Reviewed on 0ctober 5, 2016

Accepted on 0ctober 21, 2016
DOI

10.17219/acem/66209

\section{Copyright}

Copyright by Author(s)

This is an article distributed under the terms of the

Creative Commons Attribution Non-Commercial License

(http://creativecommons.org/licenses/by-nc-nd/4.0/)

\begin{abstract}
Background. The decalcification of enamel leads to an increase in tissue roughness. The development of carious lesions may be halted or these lesions may heal, which results in a smoother surface.

Objectives. The objective of the study was to assess the impact of selected agents on the roughness of demineralized enamel on the smooth surfaces of teeth.

Material and methods. A total of 25 samples with exposed enamel surfaces were examined in the study. The samples were randomized into groups and they were exposed to a demineralizing solution, after which the following agents were applied: Icon (IC), Elmex gel (EI), GC Tooth Mousse (TM), Colgate Total $(K+)$ - a positive control group, and distilled water as a negative control group (K-). The impact of selected agents on the roughness of demineralized enamel was assessed with a profilometer. The parameters Ra, Rz and Rq were analyzed.

Results. Following infiltration and demineralization, the Ra coefficient declined in groups $\mathrm{IC}, \mathrm{TM}, \mathrm{K}+$ and $\mathrm{K}-$-, Rz decreased in groups IC, TM and Rq was lower in groups IC, TM and K- after using agents when compared with demineralization. The lowest Ra, Rz and Rq values, i.e. the highest degree of surface smoothness, were observed in group lc. An increase in all coefficients ( $R a, R z$ and $R q$ ) was noted in group El.

Conclusions. Demineralized enamel can be smoothed out through the one-time application of Icon resin or the long-term application of GC Tooth Mousse. The least effective agents turned out to be those with a high fluoride content.
\end{abstract}

Key words: enamel, infiltration, roughness, early carious lesion, demineralization 


\section{Introduction}

The contemporary definition of dental caries is as follows: "caries is a dynamic, complex, multifactorial process involving the gradual loss of mineral compounds from hard dental tissue." It begins with lesions in the enamel and the only reversible stage in this process is initial caries, clinically visible as a white or brownish spot.

Human enamel has unique properties resulting from its structure, namely its considerable hardness $\left(8^{\circ}\right.$ on the Mohs scale), its great resistance to crushing and abrasion, its high elasticity modulus, as well as its stability in the constantly changing conditions of the oral environment. The very tight compaction of the crystals means that enamel is semi-translucent, and has a glass-like appearance. However, its surface is not perfectly smooth. Enamel features a perikymata pattern with rows of pits, representing the endings of Tomes' processes. ${ }^{2}$

In physiological conditions, the surfaces of teeth are in a state of constant, alternating periods of demineralization and remineralization. The course of the disease is dynamic, especially at the early carious lesion stage. ${ }^{3}$ This is especially important in the context of prophylaxis and treatment using minimally invasive methods. If the rate of remineralization exceeds the rate of demineralization, a carious lesion may stop developing or heal, which results in a smoother surface. ${ }^{1,4,5}$ On the other hand, demineralization leads to an increase in the porosity and roughness of the enamel.

The methods used to measure the surface geometry parameters (SGP), including roughness, are divided into contact and non-contact approaches. The most common of these is the contact technique, which makes use of a profilometer. It possesses a head equipped with a metal or diamond, tapered needle with a diameter of around 2-20 $\mu \mathrm{m}$, which registers surface irregularities.

Roughness signifies optically recognizable or mechanically palpable surface irregularities that are not a result of its shape. Roughness is described using various parameters. The most frequently used coefficients in tests for caries are the following: $\mathrm{Ra}$ - mean arithmetic deviation of the roughness profile, $\mathrm{Rz}$ - height of roughness on a 10-point scale, $\mathrm{Rq}$ - root mean square of profile deviation, and Rt - maximum height of roughness profile. ${ }^{6-9}$

Testing enamel surface roughness is a useful means of assessing the activeness and stage of a carious lesion. In the conditions of the oral cavity it has great significance for the colonization and retention of bacteria. Bearing in mind the microbial aetiology of caries, smoothing out the enamel surface, can thus play an important role in preventing this disease. ${ }^{10}$ In addition, a perfectly smooth surface ensures a shine, which improves the overall visual acceptance of the color of a tooth.

The objective of the study was to assess the impact of selected agents of various composition and mechanisms of action (Icon, GC Tooth Mousse and Elmex gel) on the roughness of demineralized enamel located on the smooth surfaces of teeth.

\section{Material and methods}

\section{Material used}

The following agents were applied in the study: Icon low viscosity resin (DMG Germany), Elmex gel (GABA GmbH, Germany) containing 12,500 ppm F - in the form of the amine fluorides Olaflur and Dectaflur, as well as sodium fluoride, GC Tooth Mousse cream (GC, Japan) containing CPP-ACP (casein phosphopeptide and amorphous calcium phosphate), Colgate Total paste (ColgatePalmolive, Poland) with 1,450 ppm F content in the form of sodium fluoride.

\section{Preparation of samples}

In the study we used human molars and premolars extracted for different dental reasons from patients aged $18-35$ years, which were then stored in a $0.1 \%$ thymol solution. To qualify for the study, the teeth had to be healthy, without defects or fillings. A total of 25 samples with exposed enamel surfaces were thus acquired. They were $4 \mathrm{~mm} \times 4 \mathrm{~mm} \times 3 \mathrm{~mm}$ in size and immersed in an acrylic resin (Duracryl Plus, SpofaDental, Czech Republic). Blocks of enamel were removed with a diamond disc-cutting machine (Mecatome T 201 A, Presi, France). The samples were ground down with abrasive discs (grades $600 \mathrm{P}, 1200 \mathrm{P}, 2400 \mathrm{P}$ and $4000 \mathrm{P}$ ) for $60 \mathrm{~s}$, and polished using a polishing paste with grain thicknesses of 6 and 3 microns. The samples prepared in this way were then placed in an ultrasonic washer for $10 \mathrm{~min}$.

\section{Stage 1: Preliminary measurements}

The microhardness of the enamel was determined on the basis of the Vickers hardness test method (microhardness tester from the company Zwick/Roell, Germany) by applying a load of $200 \mathrm{~g}$ for $10 \mathrm{~s}^{11}$ Seven measurements were taken for each sample, after which the results were averaged. Based on the preliminary microhardness results, the samples were randomized into 5 groups (5 samples in each group), comprising 3 test groups and 2 control groups.

The surface geometry was measured with the contact method using a Surftest profilometer developed by the Japanese company Mitutoyo (model SJ-410). Three measurements were made for each sample. The enamel surface roughness was measured by analyzing the following parameters: Ra, Rz and Rq.

The Ra coefficient refers to the mean arithmetic deviation of the roughness profile from the mean line measured along the measurement or elementary segment. 
This is the mean $Z$ value from the mean line in the section of Ir segment, where $\mathrm{Z}(\mathrm{x})$ is a function of the roughness profile. Parameter $\mathrm{Ra}$ is insensitive to extreme elevations and depressions of the profile (Fig. 1).

The $\mathrm{Rz}$ coefficient represents the height of the roughness from the mean line along the elementary segment. It is the sum of $\mathrm{Rp}$ (greatest profile elevation) and $\mathrm{Rv}$ (greatest profile depression) inside the elementary segment. Being the vertical distance between the highest and lowest points of the profile $\mathrm{Rz}$ measures the dispersion of the roughness profile ordinates. Since Rz is as a rule designated as the arithmetic mean of the maximum profile heights of 5 elementary segments of the Ir roughness profile, this parameter corresponds to the averaged roughness depth according to the DIN 4768 standard (Fig. 2).

The $\mathrm{Rq}$ coefficient refers to the root mean square deviation profile from the mean line along the measured or elementary segment. It corresponds to the standard deviation of the profile ordinates. It is significantly more representative than $\mathrm{Ra}$ (Fig. 3).

\section{Stage 2: Triggering early carious lesions}

To induce early carious lesions in enamel (white spot type), we used a solution with the following composition: $2.20 \mathrm{mM} \mathrm{Ca}^{2+}, 2.20 \mathrm{mM} \mathrm{PO}_{4}{ }^{3-}, 50 \mathrm{mM}$ of acetic acid, 0.015 ppm F-, pH 4.40. ${ }^{3,10}$ The samples were stored for 3 days in a solution at room temperature, and were then assessed once more for their roughness.

\section{Stage 3: Applied agents, infiltration and remineralization procedures}

Group I (Ic) - Icon low viscosity resin + Colgate Total paste. The infiltration technique was performed in accordance with the manufacturer's recommendations. The samples were polished with grade 4000 P sandpaper.

Group II (El) - Elmex gel + Colgate Total paste. Elmex gel was applied once a week for $3 \mathrm{~min}$. It was then dried. After 2 min it was rinsed in distilled water.

Group III (TM) - GC Tooth Mousse cream + Colgate Total paste. GC Tooth Mousse was applied. The samples were protected with a parafilm for $3 \mathrm{~min}$. The paste was removed with absorbent paper and after 2 min was rinsed in distilled water.

In addition, in groups I-III Colgate Total paste was applied 2 times daily to the surface of the samples in a concentration of 1:3 with distilled water. After $3 \mathrm{~min}$ had elapsed, the samples were rinsed in distilled water, and then dried with dust-free absorbent paper (Kimwipes, Kimberly-Clark, USA).

Group IV $(\mathrm{K}+)$ - positive control - Colgate Total paste. Colgate Total paste was applied 2 times daily to the surface of the samples, in a concentration of $1: 3$ with distilled water. After 3 min had elapsed, the samples were rinsed in distilled water, and then dried with dust-free absorbent paper.

Group V (K-) - negative control - distilled water. The samples were rinsed 2 times daily for $3 \mathrm{~min}$ in distilled water. Then they were dried with absorbent paper.

Between procedures the samples were stored at a temperature of $37^{\circ} \mathrm{C}$ in artificial saliva with the following composition: $25 \mathrm{mM} \mathrm{KH}_{2} \mathrm{PO}_{4}, 24 \mathrm{mM} \mathrm{Na}_{2} \mathrm{PO}_{4}, 150 \mathrm{mM}$ $\mathrm{KHCO}_{3}, 100 \mathrm{mM} \mathrm{NaCl}, 1.5 \mathrm{mM} \mathrm{MgCl} 2,6 \mathrm{~mL} 25 \mathrm{mM}$ sodium citrate $\times 2 \mathrm{H}_{2} \mathrm{O}, 15 \mathrm{mM} \mathrm{CaCl}_{2}, \mathrm{pH}$ 6.7. ${ }^{12}$ The saliva solution was changed every day.

Remineralization procedures were performed for 4 weeks, after which the roughness of the samples was assessed.

The study was approved by the Ethics Committee (no. RNN/151/12/KE).

Table 1. Preliminary measurements of surface microhardness (SMH)

\begin{tabular}{|l|c|c|c|c|c|}
\multicolumn{1}{|c|}{ Group } & IC & El & TM & K+ \\
\hline Mean (+/SD) & $361.67(44.14)$ & $356.87(34.79)$ & $356(34.21)$ & $356.27(33.81)$ & $340.73(31.27)$ \\
\hline Median & 370.67 & 356 & 353.67 & 354 \\
\hline I quartile - III quartile & $320.33-373$ & $333.33-377$ & $335.67-384.33$ & $339.67-385$ \\
\hline Min-max & $319-425.33$ & $315-403$ & $311.67-394.67$ & $310-392.67$ \\
\hline
\end{tabular}

Table 2. Measurements of enamel surface roughness: $R a, R z, R q(\mu m)$ - mean values and standard deviation in study groups after successive stages of the study

\begin{tabular}{|c|c|c|c|c|c|c|c|c|c|}
\hline \multirow{2}{*}{ Group } & \multicolumn{3}{|c|}{ Stage 1} & \multicolumn{3}{|c|}{ Stage 2} & \multicolumn{3}{|c|}{ Stage 3} \\
\hline & $\mathrm{Ra}$ & $\mathrm{Rz}$ & $\mathrm{Rq}$ & $\mathrm{Ra}$ & $\mathrm{Rz}$ & $\mathrm{Rq}$ & $\mathrm{Ra}$ & $\mathrm{Rz}$ & $\mathrm{Rq}$ \\
\hline$|-| C$ & $0.06(0.03)$ & $0.5(0.3)$ & $0.08(0.04)$ & $1.34(0.24)$ & 7.96 (1.19) & $1.68(0.25)$ & $0.45(0.54)$ & $3.75(4.26)$ & 1.09 (1.39) \\
\hline II-El & $0.06(0.04)$ & $0.39(0.21)$ & $0.07(0.03)$ & $1.5(0.46)$ & $9.71(2.81)$ & $2.05(0.75)$ & $1.67(0.45)$ & $10.61(4.01)$ & $2.25(0.71)$ \\
\hline III-TM & $0.04(0.02)$ & $0.46(0.37)$ & $0.06(0.04)$ & $1.6(0.41)$ & 11.01 (3.39) & $2.29(0.81)$ & $1.15(0.65)$ & $7.95(4.7)$ & $1.98(1.52)$ \\
\hline IV-K+ & $0.04(0.02)$ & $0.42(0.24)$ & $0.07(0.05)$ & $1.69(0.51)$ & $10.07(2.69)$ & $2.22(0.63)$ & $1.52(0.92)$ & 10.55 (6.69) & $2.77(2.46)$ \\
\hline V-K- & $0.05(0.02)$ & $0.44(0.26)$ & $0.07(0.03)$ & $1.05(0.07)$ & $6.71(1.09)$ & $1.39(0.24)$ & $1.03(0.19)$ & $6.75(1.74)$ & $1.24(0.36)$ \\
\hline
\end{tabular}




\section{Statistical analysis}

The following basic statistical measures were used to describe variables: arithmetic mean, median, standard deviation, and range. The normal distribution of variables was determined according to the Shapiro-Wilk test. On the other hand, for inter-group comparison purposes we used nonparametric equivalents of variance analysis, i.e. the Kruskal-Wallis test (for independent groups) and the Friedman test (for dependent groups). In cases where the null hypothesis was rejected appropriate post hoc tests were conducted. The p-value $\mathrm{p}<0.05$ was established as statistically significant. STATISTICA v. 10.0 PL (StatSoft, INC, USA) software was used for statistical analysis purposes.

\section{Results}

The results were presented in tables and shown in graphic form in figures. Table 1 includes the mean values for microhardness and standard deviation in the study groups. Based on the microhardness values the samples were randomized into 5 groups. The results show that all the groups were comparable with regard to this parameter. The mean value of surface microhardness $(\mathrm{SMH})$ varied between $340.73 \pm 3.27 \mathrm{HV} \pm 31.27 \mathrm{HV}$ and $361.67 \pm 44.14 \mathrm{HV}$. No statistically significant differences ( $p=0.990$ ) were observed between groups in terms of the initial SMH values. This shows that the samples had been divided properly, so that the relative homogeneity of the study material, i.e. human teeth, had been preserved.

Table 2 presents the mean values for variables $\mathrm{Ra}, \mathrm{Rz}$ and Rq for particular groups after successive stages of the study.

No statistically significant differences were noted between the groups with regard to the initial values for $\mathrm{Ra}(\mathrm{p}=0.746)$, $\mathrm{Rz}(0.973)$ and $\mathrm{Rq}(\mathrm{p}=0.919)$ after the first stage. This indicates that comparably smooth surfaces had been achieved.

After inducing early carious lesions (stage II) there was a significant increase in $\mathrm{Ra}, \mathrm{Rz}$ and $\mathrm{Rq}$ values $(\mathrm{p}<0.001)$ in all the groups compared with stage I, which indicates roughening of the sample surfaces. There were no statistically significant differences between the groups in terms of $\mathrm{Ra}(\mathrm{p}=0.077), \mathrm{Rz}(\mathrm{p}=0.151)$ and $\mathrm{Rq}(\mathrm{p}=0.062)$ following demineralization.

Following implementation of the infiltration and remineralization procedures, the $\mathrm{Ra}$ coefficient declined in groups Ic, TM, K+ and K-, Rz decreased in groups Ic and $\mathrm{TM}$, and $\mathrm{Rq}$ was lower in groups Ic, Tm and K-compared with demineralization. The lowest $\mathrm{Ra}, \mathrm{Rz}$ and $\mathrm{Rq}$ values, i.e. the highest degree of surface smoothing, was observed in group Ic. All the coefficients ( $\mathrm{Ra}, \mathrm{Rz}$ and $\mathrm{Rq}$ ) were higher in group El. A comparison between the groups with respect to the variables $\mathrm{Ra}(\mathrm{p}=0.074), \mathrm{Rz}(\mathrm{p}=0.340)$ and $\mathrm{Rq}$ $(\mathrm{p}=0.286)$ showed no statistically significant differences following the application of the agents.
Fig. 1. Ra - arithmetic mean of roughness profile ordinates

$$
R_{a}=\frac{1}{I_{r}} \int_{0}^{I_{r}}|Z(x)| d x
$$

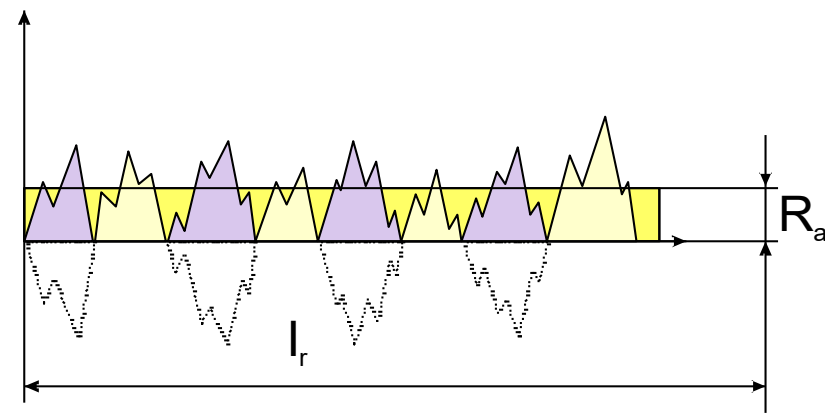

Fig. 2. Rz - maximum height of roughness profile

$$
R z=R p+R v
$$

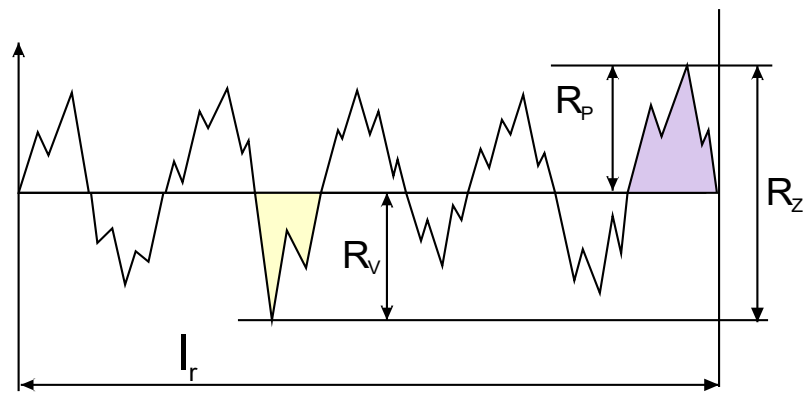

Fig. 3. $\mathrm{Rq}$ - root mean square of roughness profile ordinates

$$
R_{q}=\sqrt{\frac{1}{I_{r}} \int_{0}^{I r} Z^{2}(x) d x}
$$

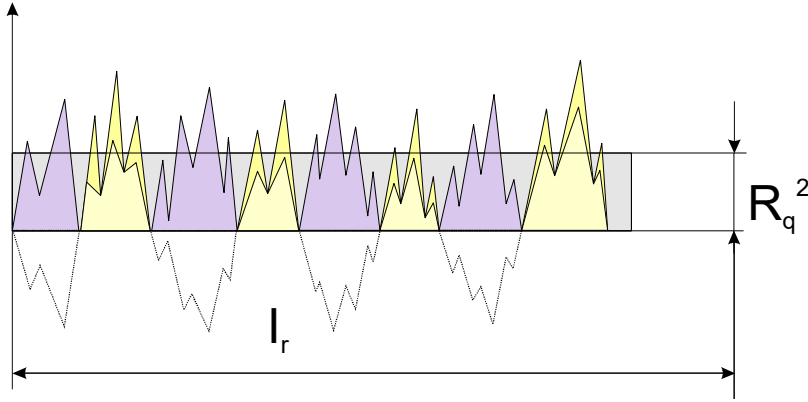

Sample graphs showing the roughness profiles for groups Ic and El, in which the lowest and highest values for $\mathrm{Ra}, \mathrm{Rz}$ and $\mathrm{Rq}$ were recorded, respectively, are presented in Fig. 4 and 5.

Figures 6-10 present the changes in the $\mathrm{Ra}, \mathrm{Rz}$ and $\mathrm{Rq}$ coefficients in the groups after different stages of the study. 
Fig. 4. Graphs showing the surface roughness profile for group Ic after successive stages of the study

\section{GROUP IC:}

\section{Stage I}

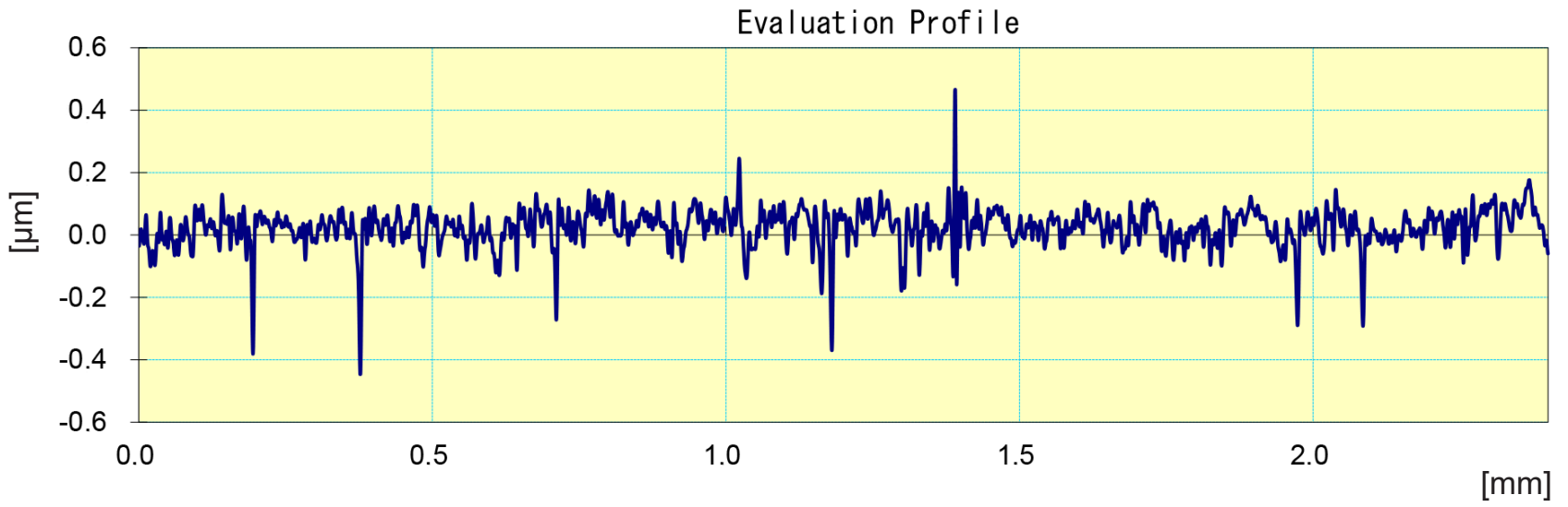

Stage II

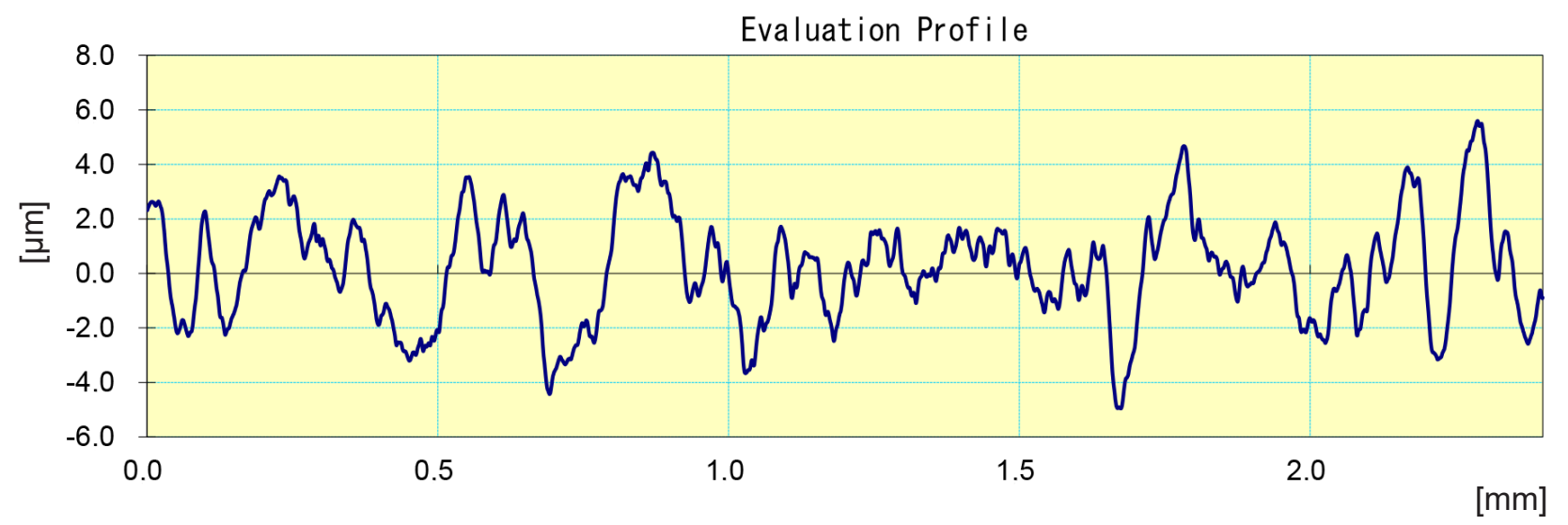

Stage III

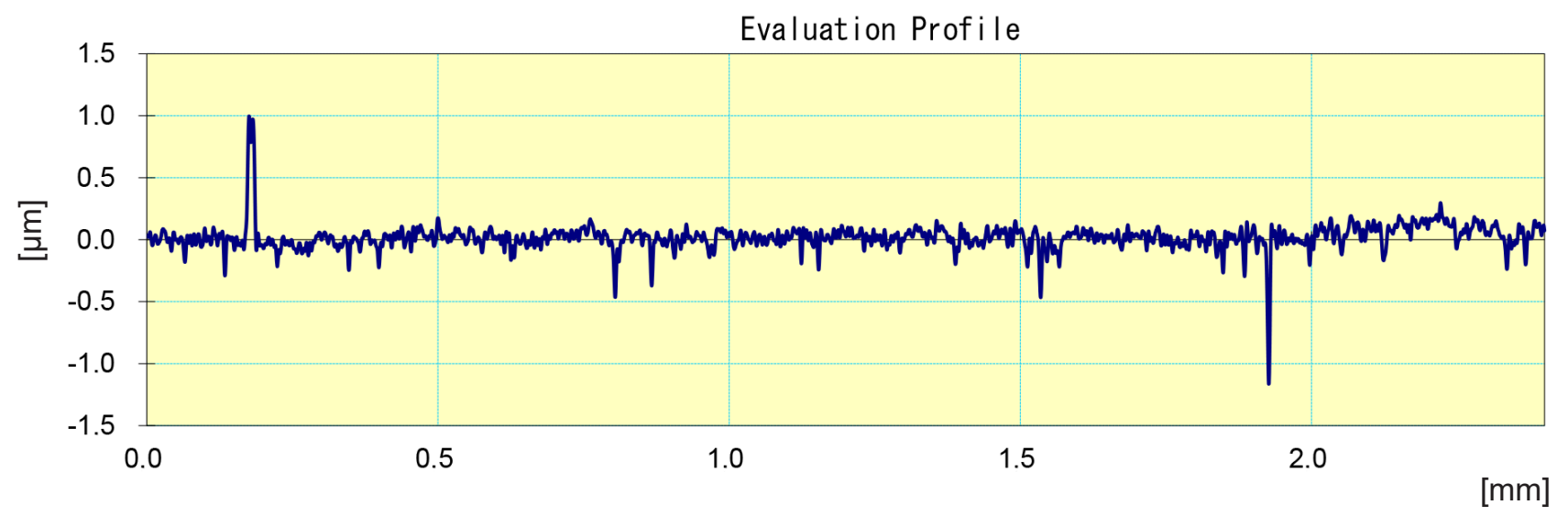


Fig. 5. Graphs showing the surface roughness profile for group E1 after successive stages of the study

\section{GROUP El:}

\section{Stage I}

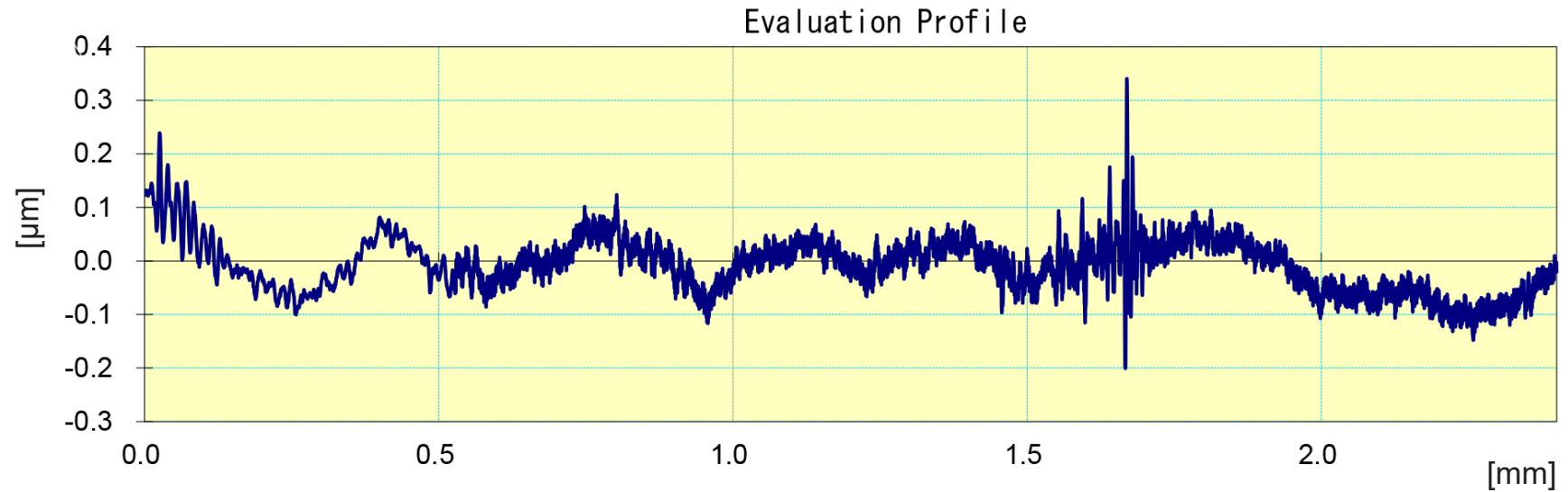

Stage II

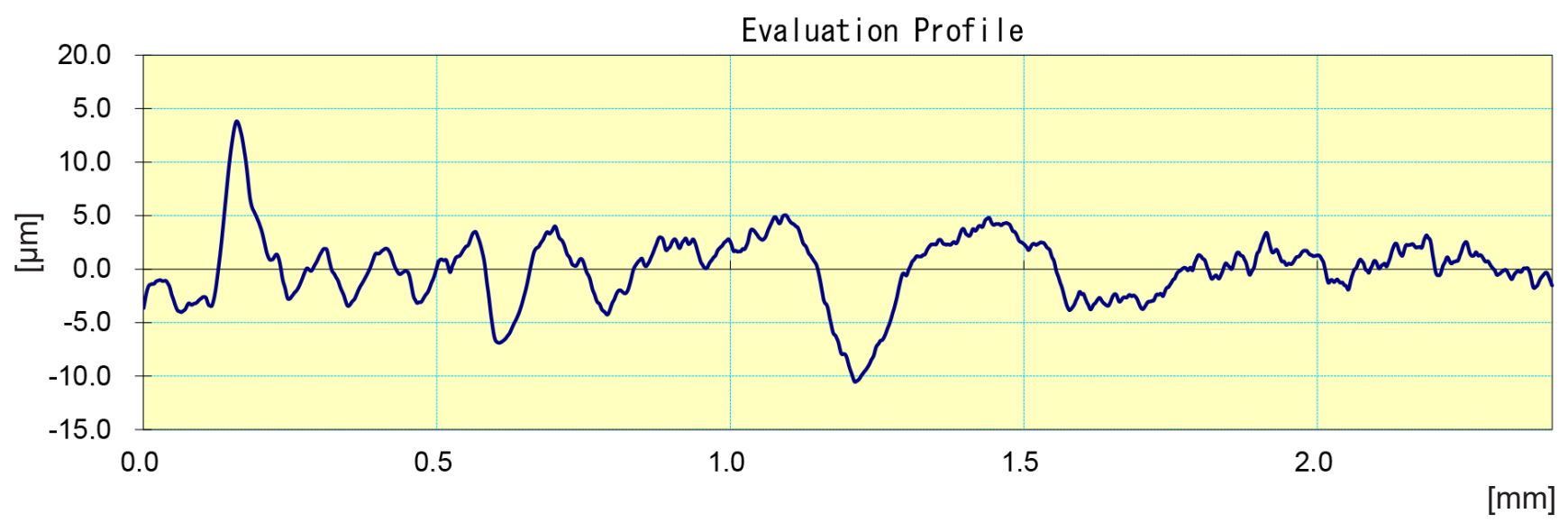

Stage III

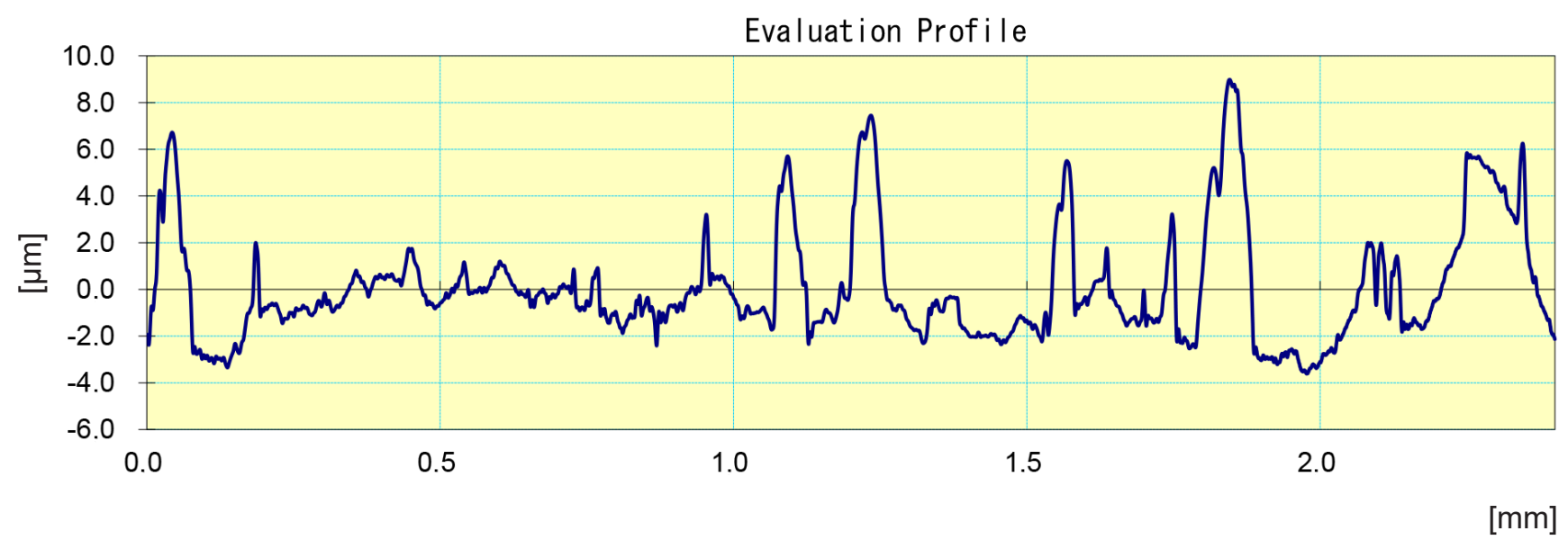


A comparison of changes in the Ra and Rz coefficients in group Ic revealed statistically significant differences between different stages of the study $(p=0.015)$. Posthoc tests revealed statistically significant differences between stages I and II. The Ra and Rq values were similar after stages I and III, which suggests the surfaces had smoothed out to the baseline level. However, these results are not statistically significant.

In group El, a comparison of the changes in the $\mathrm{Ra}, \mathrm{Rz}$ and $\mathrm{Rq}$ coefficients revealed statistically significant differences between different stages of the study (for Ra and $\mathrm{Rq} \mathrm{p}=0.015$, for Rz $\mathrm{p}=0.022$ ). Post-hoc tests confirmed differences between stages I and III. The Ra, Rz and Rq values increased after the induction of carious lesions and further rose after an agent was applied. This means that enamel surface roughness increased after successive stages of the study.

In groups TM and $\mathrm{K}+$, a comparison of changes in coefficients $\mathrm{Ra}, \mathrm{Rz}$ and $\mathrm{Rq}$ revealed statistically signifi- cant differences between different stages of the study ( $\mathrm{p}=0.022$ ). Post-hoc tests confirmed these differences between stages I and II. Following the application of GC Tooth Mousse $\mathrm{Ra}, \mathrm{Rq}$ and $\mathrm{Rz}$ declined in relation to stage II, which suggests the surfaces had smoothed out. However, these results were not statistically significant. Following the application of Colgate Total, the mean values for $\mathrm{Ra}$ declined while those for $\mathrm{Rq}$ and $\mathrm{Rz}$ rose in relation to stage II, which provides no basis for an unambiguous assessment of changes in enamel surface roughness.

In group K-, a comparison of changes in coefficients $\mathrm{Ra}, \mathrm{Rz}$ and $\mathrm{Rq}$ revealed statistically significant differences between different stages of the study (for $\mathrm{Ra}$ and $\mathrm{Rz}$ $\mathrm{p}=0.022$, for Rq $\mathrm{p}=0.015$ ). Post-hoc tests confirmed the differences between stages I and II (for $\mathrm{Ra}$ and $\mathrm{Rq}$ ) as well as between stages I and III (for Rz). The values for Ra, $\mathrm{Rz}$ and $\mathrm{Rq}$ were similar after stages II and III. No surface roughening or smoothing of the samples occurred in this group following stage III.
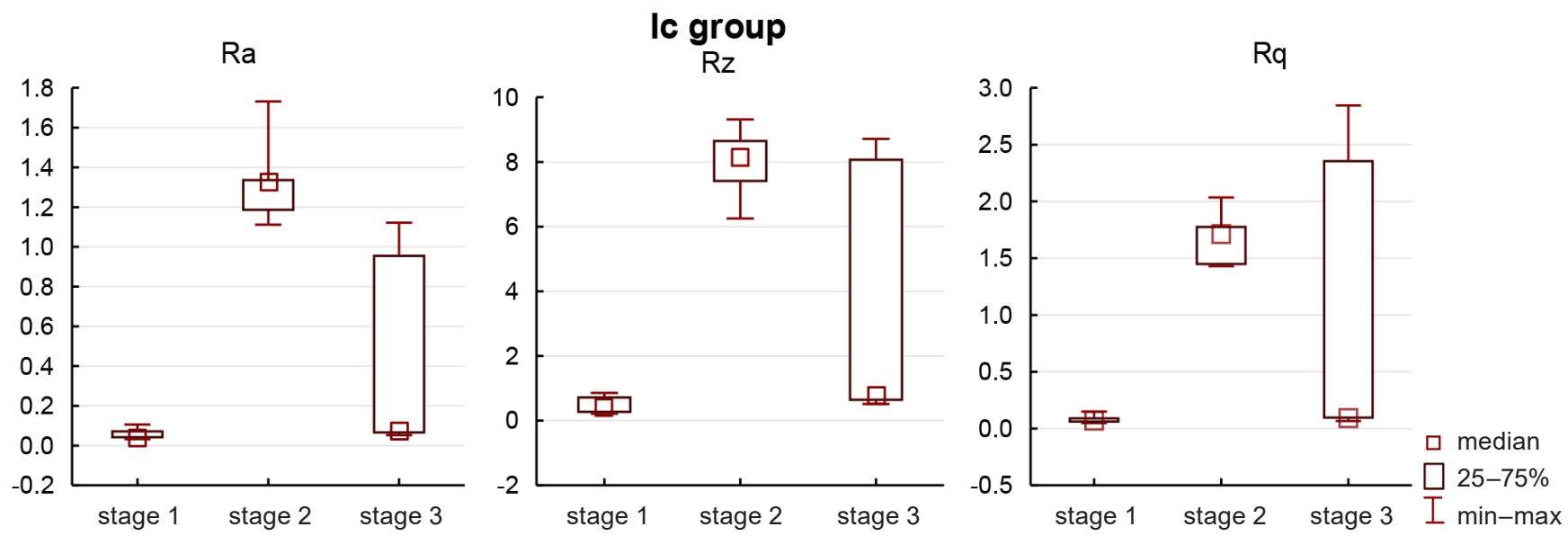

Fig. 7. Ra, Rz and Rq values in group El after successive stages of the study

$\mathrm{Ra}$

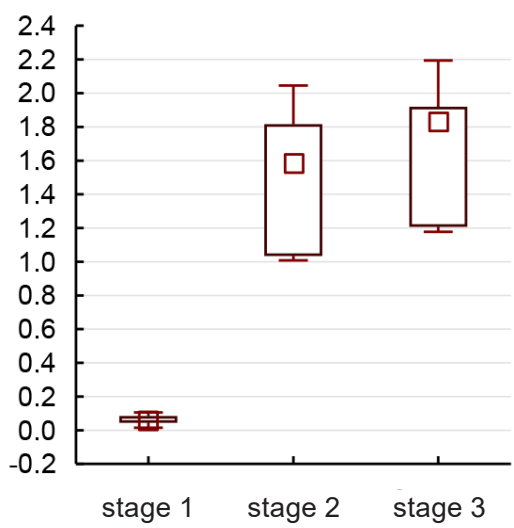

El group

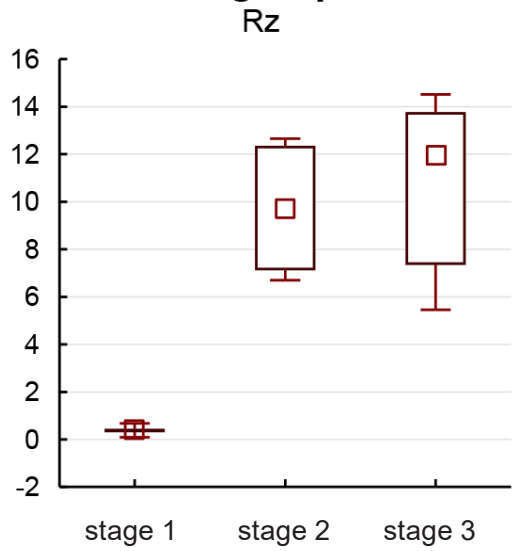

$\mathrm{Rq}$

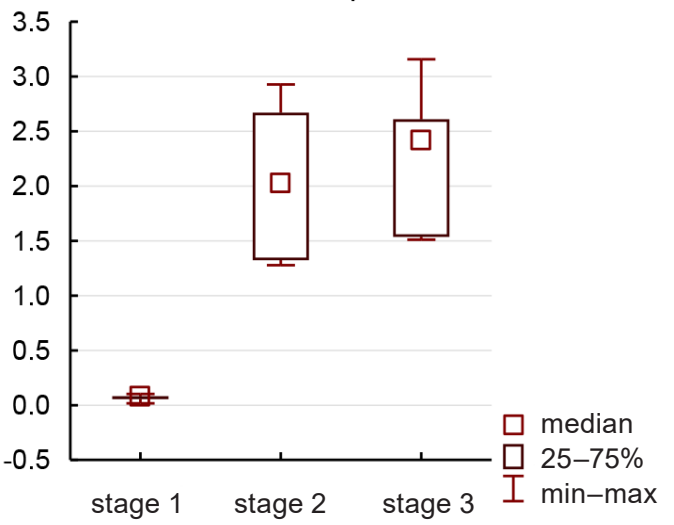


Fig. 8. Ra, Rz and Rq values in group TM after successive stages of the study
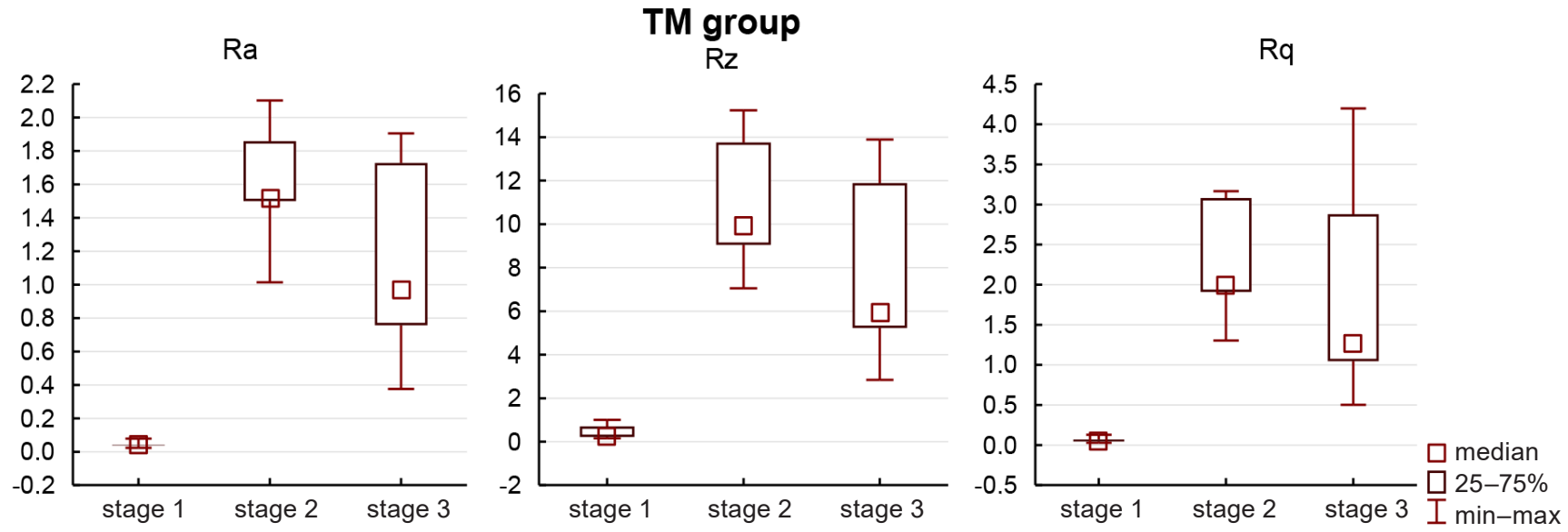

Fig. 9. Ra, Rz and Rq values in group K+ after successive stages of the study
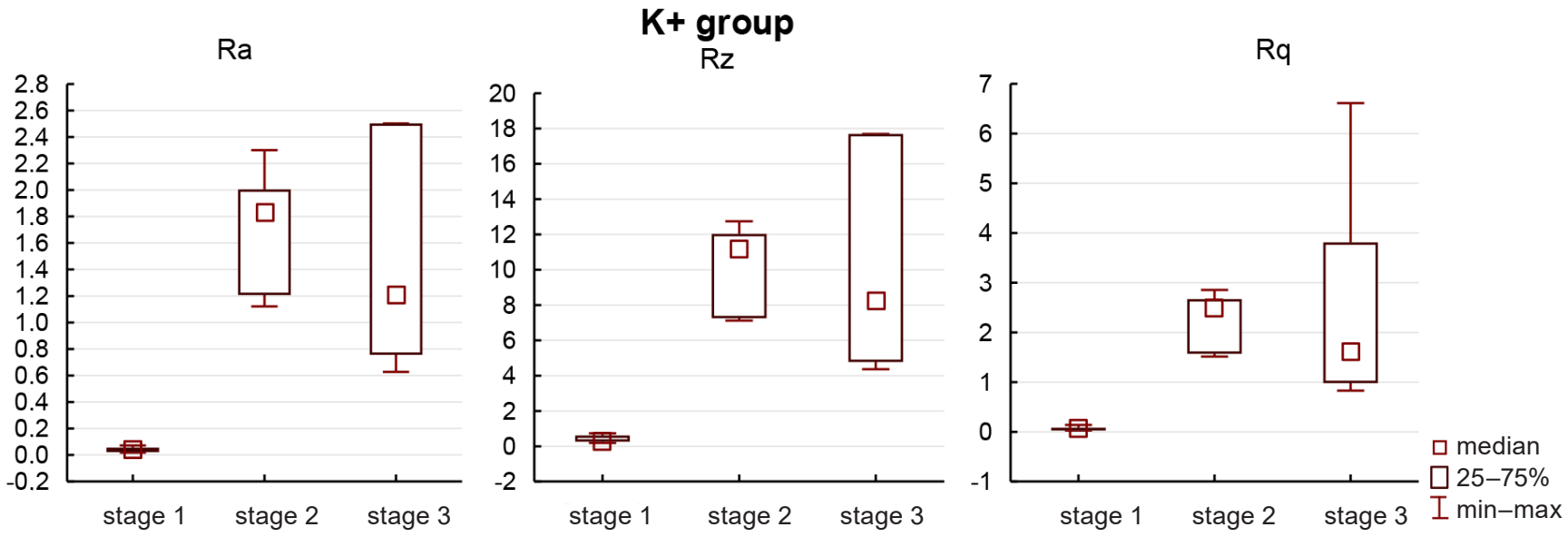

Fig. 10. Ra, Rz and Rq values in group K- after successive stages of the study

$\mathrm{Ra}$

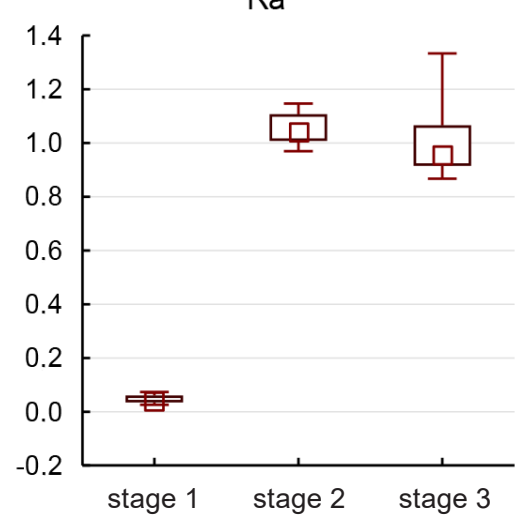

K- group

$\mathrm{Rz}$

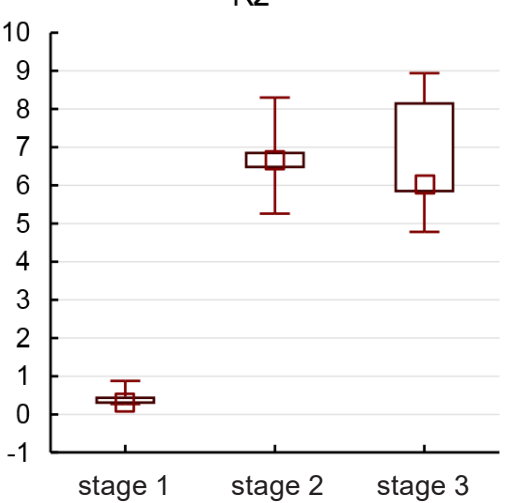

$\mathrm{Rq}$

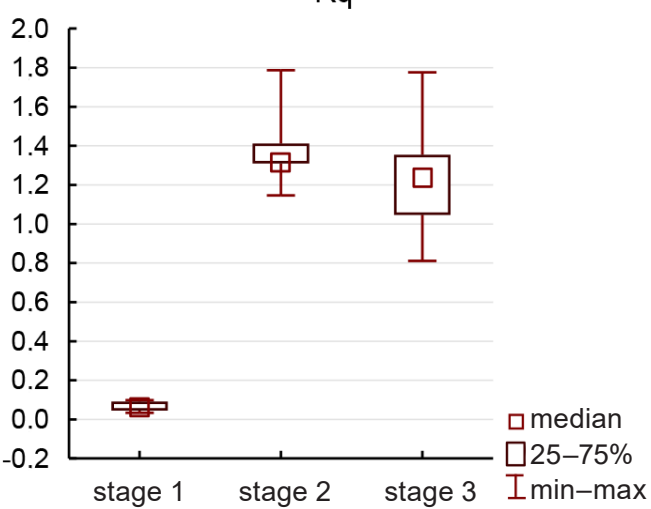




\section{Discussion}

When discussing the enamel surface roughness results, we should bear in mind the fact that the first stage in the experiment involved polishing the samples with the aim of ensuring their surfaces were uniform. As Attin reports, this is a commonly used procedure in the in vitro enamel and dentin texture tests. This is because it allows for precise measurements when slight surface smoothing or roughening occurs as a result of chemical or mechanical processes. ${ }^{13}$ The hard tissue of a tooth is perfectly smooth. Creating flat enamel samples immersed in acrylic resin without removing the surface layer of tissue appears impossible due to the morphological structure of teeth, their natural curvature, protuberances and depressions, etc. This is shown by the preliminary results for roughness - differences were noted in the $\mathrm{Ra}, \mathrm{Rz}$ and $\mathrm{Rq}$ coefficients between the groups, although they were not statistically significant.

A small number of publications have analyzed the roughness of enamel surfaces with initial caries following repair procedures. Researchers have put forward a number of conclusions regarding the texture of demineralized enamel surfaces treated with medicinal agents and based on the following parameters: $\mathrm{Ra}$ or $\mathrm{Ra}$, and $\mathrm{Rz}$ or $\mathrm{Ra}, \mathrm{Rq}$ and Rt. ${ }^{6-9} \mathrm{Ra}$ is the basic coefficient used to assess surface roughness. Whitehead et al. conclude that this widely applied coefficient is not sensitive to the shape of a surface - it does not illustrate it precisely, and therefore should not be used on its own to describe roughness. To make an accurate assessment of the surface roughness of the enamel samples in the present study, we analyzed 3 variables, namely $\mathrm{Ra}, \mathrm{Rz}$ and $\mathrm{Rq}$.

After inducing early carious lesions we observed a significant increase in the $\mathrm{Ra}, \mathrm{Rz}$ and $\mathrm{Rq}$ coefficients in all the groups. The implementation of procedures based on the agents assessed in this study led to changes in the $\mathrm{Ra}, \mathrm{Rz}$ and $\mathrm{Rz}$ coefficients in all the groups in relation to both, the first and second stages. The highest degree of surface smoothing was achieved by infiltrating the lesions with Icon resin.

In the case of the group in which Icon was applied, the excess material was removed prior to polymerization and after curing. The samples were polished in accordance with the manufacturer's recommendations and the indications from the literature. The method of polishing the samples with sandpaper (P 4000) for $20 \mathrm{~s}$ was taken from a publication, in which researchers demonstrated that around $125 \mu \mathrm{m}$ of resin can be removed in this way, which represents the average excess volume of the agent following its polymerization. ${ }^{14}$ Chinese researchers have also pointed out the need to polish teeth following infiltration with a low viscosity resin. An assessment of $\mathrm{Ra}$ and $\mathrm{Rz}$ coefficients in an in vitro test revealed a significant increase in roughness following the application and polymerization of the agent. Polishing the surface of the samples with rubbers and discs with low coarseness clearly smoothed out the surfaces. ${ }^{8}$ In light of these studies it would appear legitimate to presume that smoothing of the surfaces infiltrated with low viscosity resin was possible thanks to sanding the samples. However, Arslan et al. are of the opinion that the infiltration technique reduces roughness thanks to the sealing of the resin's micropores. The authors compared the use of an infiltrant with a light-curing binding material that released fluoride and varnish with amorphous calcium phosphate (ACP), on the one hand, with fluorine without preliminary polishing of samples, on the other, and noted a much smoother surface when Icon was applied. The second part of their experiment confirms this observation - the researchers demonstrated less adhesion of Streptococcus mutans to enamel, which should likewise be explained by the smoothness of the surface. ${ }^{6}$

In the present study, following the application of GC Tooth Mousse the texture of the enamel improved in comparison with the second stage. Other authors assessed in in vitro conditions an enamel surface that had been subject to abrasion and then 10\% CPP-ACP. They claimed that the application of the agent had helped improve the texture of the tooth surface in comparison with what had been achieved following microabrasive procedures. Researchers claimed that the above-described "smoothing properties" was due to the pores being filled with calcium and phosphate ions. Elkassas \& Arafa noted a significant reduction in the properties of the Ra coefficient after a 2-week remineralization procedure using calcium-phosphate agents. ${ }^{7}$ Surface smoothing occurred with the continued use of products containing functionalized tricalcium phosphate ( $f$ TCP), ACPF and CPPACPF for another 2 weeks, although after the samples had been immersed in an acidic solution there was a significant increase in the Ra coefficient.

CPP-ACP ensures a high gradient of calcium and phosphate ions in an enamel environment, which facilities remineralization. The efficacy of CPP-ACP is reinforced in the oral environment when saliva is present. ${ }^{15,16}$

Following the application of a high fluoride product, i.e., Elmex gel, the surface roughness increased in relation to the demineralized enamel. What is interesting to note is that the $\mathrm{Ra}, \mathrm{Rz}$ and $\mathrm{Rq}$ values in these groups were higher than in the negative control group.

The authors of other experiments likewise failed to observe any improvement in this parameter after using agents with a high fluoride content. Jardim et al. studied in situ the local application of a paste with 1100 ppm fluoride and an acidified phosphate fluoride gel (APF), and did not report any statistically significant differences in roughness (Ra coefficient) between the following stages: preliminary, post-demineralization and post-remineralization. ${ }^{17}$ In their opinion, initial polishing of samples may result in relatively less smooth enamel surfaces following repair procedures. Chen et al. assessed the roughness of maturation 
stage enamel crystals in the incisors of rats. ${ }^{18}$ They immersed them in a fluoride solution of varying concentration (0-20,000 ppm, NaF) and observed that an increase in the concentration of fluoride ions was paralleled by an increase in the surface roughness of the crystals. The authors concluded that this happens most probably as a result of restructuring of the surface due to an ion exchange, the dissolution and redeposition of ions, the formation of calcium fluoride and other calcium complexes.

Enamel surface roughness plays an important role in the context of caries prevention. The degree of surface smoothing has an impact on the adhesion of bacteria (the main factor initiating caries) and the potential for dental plaque to develop in the oral environment. The critical threshold for surface roughness allowing microorganisms to settle has been set at $0.2 \mu \mathrm{m}$ for the $\mathrm{Ra}$ coefficient. Surface roughness above this value is accompanied by a significant increase in the accumulation of bacterial plaque. On the other hand, smoothing below this threshold value has no effect on the adhesion and colonization of microorganisms. ${ }^{16,19}$

In the current study, such values were only achieved in a small number of cases following infiltration of the samples with a low viscosity resin.

It is difficult to compare the enamel surface roughness results obtained in the present study with the publications cited from the literature. The experiments conducted by the small number of authors referred to above took place in different conditions to those described in the present study. Moreover, any comparisons made between sanded samples and enamel samples that were not polished prior to being measured may lack objectivity. Despite the difficulties described above, the authors wanted to draw attention to the need to assess the effectiveness of repair procedures for early carious lesions in terms of their impact on enamel texture.

The highest degree of enamel surface smoothing was achieved with a low viscosity resin Icon and after polishing the samples. Likewise, the long-term application of GC Tooth Mousse helped improve the texture of demineralized enamel. On the other hand, the use of high fluoride agents resulted in increased roughness of the decalcified tissue.

\section{References}

1. Usha C, Sathyanarayanan R. Dental caries - A complete changeover (Part I). J Conserv Dent. 2009;12(2):46-54.

2. Dabanoglu A, Wood C, García-Godoy F, Kunzelmann KH. Whitening effect and morphological evaluation of hydroxyapatite materials. Am J Dent. 2009;22(1):23-29.

3. Clark KD. The efficacy of $37 \%$ phosphoric acid + Mi Paste Plus on remineralization of enamel white spot Plus on remineralization of enamel white spot lesions [master's thesis]. lowa, USA: University of lowa; 2011.

4. Featherstone JD. The continuum of dental caries - Evidence for a dynamic disease process. J Dent Res. 2004;83:C39-C42.

5. Ellwood R, Goma J, Pretty I. Caries clinical trial methods for the assessment of oral care products in the $21^{\text {st }}$ century. Adv Dent Res. 2012;24(2):32-35.
6. Arslan S, Zorba YO, Atalay MA, et al. Effect of resin infiltration on enamel surface properties and Streptococcus mutans adhesion to artificial enamel lesions. Dent Mater J. 2015;34(1):25-30.

7. Elkassas D, Arafa A. Remineralizing efficacy of different calciumphosphate and fluoride based delivery vehicles on artificial caries like enamel lesions. J Dent. 2014;42(4):466-474.

8. Yuan CQ, Dou GW, Deng J, Geng GL, Sun P, Cao YX. Effect of infiltration technique and polishing on the roughness of artificial carious enamel surfaces. Shanghai Kou Qiang Yi Xue. 2013;22(4):402-406.

9. Zhihong $D$, Jiang $C$, Yue Z, Kaili L. In vitro remineralization of human dental enamel by bioactive glasses. J Mater Sci. 2011;46:1591-1596.

10. FrazierMC, SouthardTE,DosterPM.Prevention of enamel demineralization during orthodontic treatment: An in vitro study using pit and fissure sealants. Am J Orthod Dentofacial Orthop. 1996;110:459-465.

11. Haghgoo R, Rezvani MB, Salehi Zeinabadi M. Comparison of nanohydroxyapatite and sodium fluoride mouthrinse for remineralization of incipient carious lesions. J Dent (Tehran). 2014;11(4):406-410.

12. Ardvidson K, Johansson EG. Galvanic current between dental alloys in vitro. Scand J Dent Res. 1985;93:467-473.

13. Attin T. Methods for assessment of dental erosion. Monogr Oral Sci. 2006;20:152-172.

14. Torres CR, Borges AB, Torres LM, Gomes IS, de Oliveira RS. Effect of caries infiltration technique and fluoride therapy on the colour masking of white spot lesions. J Dent. 2011;39(3):202-207.

15. Najibfard K, Ramalingam K, Chedjieu I, Amaechi BT. Remineralization of early Caries by a nano-hydroxyapatite dentifrice. J Clin Dent. 2011;22(5):139-143.

16. Mathias J, Kavitha S, Mahalaxmi S. A comparison of surface roughness after microabrasion of enamel with and without using CPPACP: An in vitro study. J Conserv Dent. 2009;12(1):22-25.

17. Jardim JJ, Pagot MA, Maltz M. Artificial enamel dental caries treated with different topical fluoride regimes: An in situ study. J Dent. 2008;36(6):396-401.

18. Chen H, Czajka-Jakubowska A. Effects of systemic fluoride and in vitro fluoride treatment on enamel crystals. J Dent Res. 2006;85(11):1042-1045.

19. Bollen C, Lambrechts P, Quirynen M. Comparison of surface roughness of oral hard materials to the threshold surface roughness for bacterial plaque retention: A review of the literature. Dent Mater. 1997;13(4):258-269. 